\title{
Imagery rescripting of traumatic memories for panic disorder: an exploratory study
}

\author{
Takayuki Shibuya ${ }^{1,2 *}$, Yoichi Seki ${ }^{4}$, Shinobu Nagata ${ }^{1}$, Tomokazu Murata ${ }^{1}$, \\ Yoichi Hiramatsu ${ }^{1}$, Fuminori Yamada ${ }^{1}$, Mizue Yokoo ${ }^{1}$, Hanae Ibuki ${ }^{1}$, \\ Noriko Minamitani ${ }^{3}$, Mari Tanaka ${ }^{3}$ and Eiji Shimizu ${ }^{1,3,4}$ \\ ${ }^{1}$ Research Center for Child Mental Development, Chiba University, Chiba, Japan \\ ${ }^{2}$ Chiba Psychiatric Medical Center, Chiba, Japan \\ ${ }^{3}$ Department of Cognitive Behavioral Physiology, Graduate School of Medicine, Chiba University, \\ Chiba, Japan \\ ${ }^{4}$ Cognitive Behavioral Therapy Center, Chiba University Hospital, Chiba, Japan
}

Received 28 July 2017; Accepted 9 March 2018

\begin{abstract}
Imagery rescripting ( $\operatorname{ImRs)}$ is a psychological intervention designed to change the meaning of images and associated memories and reduce emotional distress. Recent studies have shown that ImRs can be successfully applied to many psychological problems and disorders; however, little has been reported on the application of ImRs for panic disorder (PD). Consequently, we explored the therapeutic effects of ImRs on patients with PD. Fifteen patients with PD received 16 individual cognitive behavioural therapy (CBT) sessions weekly, including one ImRs session. Early traumatic memories associated with recurrent images in panic situations were identified and rescripted to alleviate maladaptive encapsulated beliefs. ImRs ratings (vividness and distress of the images and memories and conviction degree of encapsulated beliefs) were measured prior to and after ImRs. Self-negative contents not directly related to symptoms of panic attack were observed as common themes in the worst meaning of the image, the memory, and in the encapsulated belief. Whilst five (33\%) patients had anticipatory anxiety, $10(67 \%)$ patients had other self-negative beliefs. ImRs significantly reduced distress from images, memories and encapsulated beliefs; however, it did not change the vividness of images and memories. There was no significant correlation between the reduction in PD severity over the CBT program and the change in each ImRs rating. The results of this study are promising for certain aspects of panic disorder. However, further research is needed to overcome the limitations of this study.
\end{abstract}

Key words: panic disorder, cognitive behavioural therapy, traumatic stress, memory, belief

\footnotetext{
*Author for correspondence: Takayuki Shibuya, Research Center for Child Mental Development, Chiba University, 1-8-1 Inohana, Chuo-ku, Chiba-shi, Chiba 260-8670, Japan (email: ys543724@wd5.so-net.ne.jp).

(c) British Association for Behavioural and Cognitive Psychotherapies 2018.

This is an Open Access article, distributed under the terms of the Creative Commons Attribution licence (http://creativecommons.org/licenses/by/4.0/), which permits unrestricted re-use, distribution, and reproduction in any medium, provided the original work is properly cited.
} 


\section{Introduction}

Interest in and applications of imagery rescripting (ImRs) are rapidly increasing (Arntz, 2012; Hagennars and Holmes, 2012). ImRs is a set of therapeutic techniques addressing specific memories of earlier experiences associated with present problems (Arntz, 2012). In an ImRs procedure, aversive autobiographical memories are rendered less unpleasant or emotional (Slofstra et al., 2016). ImRs describes a set of therapeutic techniques aimed at changing these negative meanings (Stopa, 2011). According to a historical review on ImRs by Edwards (2007), in the late 1980s and early 1990s, therapists such as Jeff Young (schema-focused therapy) and Mary-Ann Layden (personality disorder treatment) started to fully explain the application of imagery-based techniques in the framework of cognitive therapy (Young and Lindemann, 1992; Layden et al., 1993). Smucker developed an imagery-focused treatment for adult survivors of childhood sexual abuse, designed to alleviate post-traumatic stress disorder (PTSD) symptomatology and alter abuse-related beliefs and schemas (Smucker et al., 1995).

Arntz and Weertman (1999) expanded ImRs to include patients with personality disorders and attempted to address individual problems rooted elsewhere than childhood sexual abuse. Since then, the application of ImRs to many psychiatric disorders has been studied and practised: social anxiety disorder (SAD) (Wild et al., 2007, 2008; Wild and Clark, 2011; Nilsson et al., 2012; Lee and Kwon, 2013; Frets et al., 2014; Reimer and Moscovitch, 2015; Norton and Abbott, 2016), PTSD (Arntz et al., 2007; Long and Quevillon, 2009; Hackmann, 2011; Afkham and Toghchi, 2012; Arntz et al., 2013; Hoffart et al., 2013; Prasko et al., 2015; Raabe et al., 2015), depression (Patel et al., 2007; Wheatley et al., 2007; Brewin et al., 2009; Moritz et al., 2014), bulimia nervosa (Ohanian, 2001), ophidiophobia (snake phobia) (Hunt and Fenton, 2007), cancer patients with psychological distress and maladaptive adjustment derived from intrusive memories (Whitaker et al., 2010), trauma-related nightmares (Long et al. 2011a,b), pain sufferers (Philips and Samson, 2012), psychosis patients with auditory hallucinations (Ison et al., 2014), bowel/bladder control anxiety (Pajak and Kamboj, 2014), obsessive compulsive disorder (OCD) (Veale et al., 2015), and body dysmorphic disorder (Ritter and Stangier, 2016; Willson et al., 2016). However, our review of the literature failed to find any study on the application of ImRs to panic disorder (PD).

$\mathrm{PD}$ is an anxiety disorder characterized by recurring, unexpected panic attacks. A panic attack is an abrupt surge of intense fear or intense discomfort that reaches a peak within minutes, and during which time at least four of 13 panic symptoms occur. In the general population, the 12-month prevalence estimate for PD across the USA and several European countries is about 2-3\% in adults and adolescents (American Psychiatric Association, 2013). As with many anxiety and depressive disorders, PD is often co-morbid with other psychological disorders and is associated with functional disability (e.g. social and occupational impairment; Kessler et al., 2006). Although selective serotonin re-uptake inhibitors remain a first-line pharmacotherapy of PD (Batelaan et al., 2011), cognitive behavioural therapy (CBT) has been shown to be more effective than pharmacotherapy. Clark et al. (1994) compared cognitive therapy, applied relaxation, imipramine (mean $233 \mathrm{mg} / \mathrm{day}$ ), or a 3-month wait followed by allocation to treatment. During treatment, patients had up to 12 sessions in the first 3 months. Imipramine was gradually withdrawn after 6 months. Comparisons between treatments showed that at 3 months, cognitive therapy was superior to both applied relaxation and imipramine on most measures. Between 6 and 15 months, several imipramine patients relapsed. At 15 months, cognitive therapy was again superior to 
both applied relaxation and imipramine. Furthermore, Roshanaei-Moghaddam et al. (2011) conducted a meta-analysis comparing CBT and pharmacotherapy, with or without placebo, in adults with major depressive or anxiety disorders. The primary effect size was calculated from disorder-specific outcome measures as the difference between CBT and pharmacotherapy outcomes (i.e. positive effect size favours CBT; negative effect size favours pharmacotherapy). The authors found that effects for PD significantly favoured CBT over medications $(.50,95 \%$ CI: 0.02, 0.98).

CBT for PD has been developed based on Clark's (1986) cognition model of panic attacks. Clark's approach is based on the idea that panic attacks are frequently the result of misinterpreting normal bodily sensations as a sign of an impending physical or mental catastrophe (such as a heart attack or going mad) (Clark et al., 1997). This misinterpretation generates a feedback effect where anxiety, physical symptoms and negative thoughts reinforce each other.

Salkovskis et al. (1999) later added the hypothesis that safety-seeking behaviours play an important role in maintaining anxiety, because they prevent patients from benefiting from a disconfirmatory experience. Therefore, many versions of CBT for PD that are currently being performed seek to identify and change mistaken beliefs about physical symptoms and their consequences. Furthermore, it is an integral part of CBT for PD to conceptualize avoidance behaviours, a maintenance factor for PD, and to confront feared stimuli and situations (American Psychiatric Association, 2009).

Intrusive images and traumatic memories of patients with PD have not yet been fully studied. Day et al. (2004) explored recurrent images in patients with agoraphobia and found that all participants with agoraphobia (but no control participants) reported experiencing distressing, recurrent imagery in agoraphobic situations. The imagery was reported as being associated with unpleasant memories of events. Wenzel et al. (2006) developed the Panic Beliefs Inventory (PBI) to assess the dysfunctional attitudes and beliefs that panic patients have about specific symptoms and panic in general. An exploratory factor analysis on a large sample of panic patients revealed that the instrument was divided into four factors - Anticipatory Anxiety, Physical Catastrophes, Emotional Catastrophes, and SelfDeprecation - that were later translated into four scales that could be summed to obtain a total score, reflecting the higher order construct of maladaptive panic beliefs. Wenzel and Cochran (2006) examined the retrieval of autobiographical memories prompted by automatic thoughts representative of maladaptive schema content specific to PD, SAD and non-anxious participants. Panic participants retrieved memories cued with panic disorderrelated automatic thoughts more quickly than SAD and non-anxious participants, indicating that panic participants were characterized by general threat-relevant autobiographical memory biases. Considering these studies, PD patients may be significantly influenced by limited information from past traumatic events when processing current panic situations. Thus, in the same way that ImRs has been shown to be effective in SAD (Wild et al., 2007, 2008; Wild and Clark, 2011), rescripting traumatic memory in images may result in improvement in PD patients.

There is an option to apply a PTSD protocol as per Ehlers and Clark (2000) to panic patients. Just like traumatic experiences, panic attacks are perceived as sudden, overwhelming and subjectively life-threatening events. In addition, in PD with agoraphobia, patients typically respond to a panic attack with intense fear and helplessness. This means that some of the memory characteristics in PTSD trauma memory should also characterize memory of 
severe panic attacks in PD of agoraphobia patients (Hagenaars et al., 2009). The reason for choosing ImRs instead of a PTSD protocol in this study was that PD trauma memories had less re-experiencing elements than PTSD trauma memories (Hagenaars et al., 2009). Thus, the traumatic memory of patients with PD is not as fragmented as that of patients with PTSD, and therefore does not require much elaboration. The purpose of this study was to add ImRs to conventional CBT for PD patients and to explore its effectiveness.

\section{Method}

\section{Study design}

Our study was conducted in a single-arm, uncontrolled trial of individual CBT for PD in a Japanese clinical setting (Seki et al., 2016), registered in the National UMIN Clinical Trials Registry (ID: UMIN000022693).

\section{Participants}

Fifteen patients were enrolled through clinical referrals from specialist clinics and from the community via web-based advertisements, as described in Seki et al. (2016). We predicted a need for 15 participants, assuming that eight therapists were responsible for an average of 2.5 participants who were enrolled during the registration period (April 2014 to July 2016), and three-quarters of participants would withdraw; however, in this study, we excluded three patients, as they had not received an ImRs session, or there was a lack of available data concerning ImRs for these patients. Apart from that, we added three new patients via the same route within the study period. Ultimately, 15 patients were enrolled. Written, informed consent was obtained from all patients.

We used the following inclusion criteria: primary diagnosis of PD according to the Diagnostic and Statistical Manual of Mental Disorders, fifth edition (DSM-5) criteria, aged between 18 and 65 years with at least moderately severe PD [a Panic Disorder Severity Scale (PDSS) score $\geq 8$; Houck et al., 2002]. Co-morbid diagnoses were permitted if they were clearly secondary (i.e. the PD symptoms were both the most severe and the most impairing).

Exclusion criteria were as follows: psychosis, pervasive developmental disorders/mental retardation, a current high risk of suicide, substance abuse or dependence in the past 12 months, or anti-social personality disorder. All patients were evaluated by a psychiatrist using the Mini-International Neuropsychiatric Interview (Sheehan et al., 1998; Otsubo et al., 2005). Therapists and chart review confirmed treatment history. Participants' characteristics are shown in Table 1.

\section{Treatment}

Individual CBT was conducted in 16, 50-minute, weekly sessions. We developed our CBT program for PD to focus on changing catastrophic misinterpretations of bodily sensations, as per the Clark et al. model (1997). We also applied several concepts from the Clark and Wells model for SAD (1995). We added the concept of the detrimental effects of safety behaviours, attentional bias modification (attentional shift training), behavioural experiments including interoceptive exposure (systematic exposure to body sensations), ImRs, and reconsideration of worry/rumination to strengthen anticipatory anxiety. 
Table 1. Participants' baseline demographic and clinical characteristics $(N=15)$

Age (years, mean $(S D))$

$37.9(8.6)$

Sex (female, $n(\%)$ )

$13(87)$

Marital status (married, $n(\%)$ )

$6(40)$

Educational level $(<3$ years of college/university, $n(\%))$

Working status (full-time employed, $n(\%)$ )

Co-morbid agoraphobia $(n(\%))$

Co-morbid axis I diagnosis (no co-morbid condition, $n(\%)$ )

Current anti-depressant medication $(n(\%))$

Age of onset of PD (years, mean $(S D)$ )

Duration of PD (years, median (IQR))

Age at traumatic memory (years, mean $(S D)$ )

$23.8(11.3)$

Pre-PDSS score (mean $(S D))$

$13.1(4.8)$

$S D$, standard deviation; PD, panic disorder; IQR, interquartile range; PDSS, Panic Disorder Severity Scale.

The main treatment steps were as follows:

(a) Assessment

(b) Psychoeducation

(c) Case conceptualization

(d) Role play experiment with or without safety behaviour

(e) Cognitive reconstruction of catastrophic body sensation image

(f) Attention shift training

(g) Behavioural experiment

(h) ImRs of traumatic memories

(i) Modifying problematic pre- and post-event processing

(j) Comparison of belief in oneself and others for the worst situation (surveys of other people's observations)

(k) Schema work

(l) Relapse prevention

(m) Termination

The rationales for the application of some concepts from the SAD model to PD treatment are shown below:

\section{Attention shift training}

Attention shift training in this study was intended to direct participants' attention away from internal sensations. The effectiveness of attention training on patients with PD has been suggested by Wells (1990) and Wells et al. (1997). Wells (1990) reported a case of relaxationinduced anxiety in a patient with PD. He reported the use of an attention training procedure, which was effective in eliminating panic and facilitated tension reduction without producing anxiety. Wells et al. (1997) investigated the effects of attention training on panic frequency, general anxiety, and beliefs across two PD cases and one SAD case, and the results were consistent with those of a previous study (Wells, 1990) and provided preliminary evidence that 
panic attacks, anxiety and negative beliefs can be effectively and lastingly reduced through cognitive techniques that do not directly target the content of negative appraisal.

\section{Reconsideration of worry/rumination}

Reconsideration of worry/rumination in this study was intended to examine the advantages and disadvantages of post-event processing (PEP). Research on PEP, where individuals conduct a post-mortem evaluation of a social situation, has focused primarily on its relationship with SAD. Laposa et al. (2014) examined the relationship between PEP and disorder-specific symptom severity for SAD, OCD, PD and generalized anxiety disorder (GAD). PEP ratings were found to be associated with disorder-specific symptom severity in $\mathrm{SAD}, \mathrm{GAD}$ and PD, but not in OCD. The results showed that PEP might be a transdiagnostic process with relevance to a broad range of anxiety disorders, not just SAD.

The ImRs procedure in this study was based on the application of ImRs to SAD by Clark and colleagues (Wild et al., 2008; Wild and Clark, 2011). Based on three randomized controlled trials confirming the effectiveness of a cognitive therapy (CT) program and suggesting that a group format may not be advantageous (Clark et al,. 2003; Stangier et al., 2003; Mortberg et al., 2007), Clark et al. (2006) compared CT with exposure plus applied relaxation (EXP+AR), or wait-list (WAIT). CT and EXP+AR were superior to WAIT on all measures and CT led to greater improvement than EXP+AR. Percentages of patients who no longer met diagnostic criteria for social phobia at post-treatment-wait were as follows: $84 \%$ in $\mathrm{CT}, 42 \%$ in EXP+AR and $0 \%$ in WAIT. At the 1-year follow-up, differences in outcomes persisted. Wild et al. $(2007,2008)$ conducted two studies to assess the effects of ImRs alone in unselected populations of patients with SAD. The authors' ImRs protocol was broadly based on Arntz and Weertman's adaptation of the Smucker protocol (Arntz and Weertman, 1999; Smucker et al., 1995). Wild et al. (2007) reported pre- and post-rescripting results in 14 patients with SAD. The results showed that ImRs alone was associated with significant improvements in patients' negative social beliefs, the vividness and distress of their image and early memory, and in self-reported measures of social anxiety. Wild et al. (2008) then compared a session of ImRs with a control session in which images and memories were explored without being updated. The result showed that the ImRs session was associated with significantly greater improvement in negative beliefs; image, memory distress, and vividness; fear of negative evaluation; and anxiety in feared social situations. Subsequently, Wild and Clark (2011) described the importance of updating negative imagery in SAD, which is the theoretical basis for SAD.

As already mentioned, our ImRs protocol was based on Wild et al. (2008) and Wild and Clark (2011). The procedure by Wild et al. was broadly based on Arntz and Weertman's adaptation of the Smucker protocol (Arntz and Weertman, 1999; Smucker et al., 1995). The ImRs procedure in this study was as follows:

\section{Identifying the recurrent image, the linked memory and the encapsulated belief}

A semi-structured interview, based on Hackmann et al. (2000), was conducted for patients to identify recurrent images in panic situations, along with an early traumatic memory linked to the image. First, the patients were asked to recall and describe an image that appeared repeatedly in panic situations. Then, they were asked to rate the vividness and distress of the 
image. Following this, patients were asked what the image meant to them, answering these questions: 'What is the worst thing about the image?' and 'What does it mean about you as a person?'. Patients were then asked when they first remembered feeling the way they did in their image and to describe the events associated with that feeling. The patients were also asked what the early traumatic memory meant to them, answering similar questions. The patients were asked to rate the vividness and distress of the memory. Subsequently, the patients were asked to summarize the meaning of the image and the memory in one or two sentences (i.e. encapsulated belief). Lastly, they were asked to rate the degree of conviction of their encapsulated belief.

\section{Phase 1: Cognitive restructuring}

The therapists initiated the patients into a cognitive restructuring of their encapsulated belief by establishing a new perspective on their early traumatic memory. The patients were encouraged to examine the validity of their encapsulated belief by listing incongruent evidence. They were also encouraged to remember the results of behavioural experiments performed in previous CBT sessions. Through this process, the patients came to view an early traumatic memory in a more balanced way and understood that the memory was a time-limited experience without extensive implications for the present and the future.

\section{Phase 2: Imagery rescripting}

The therapists then initiated the patients into an imagery rescripting phase, which consisted of three stages:

Stage 1: The patients were asked to return to the age when they experienced the traumatic memory for the first time. They were asked to relive their memory as if the event was taking place here and now and to describe the scene of the memory in the present tense.

Stage 2: The patients were asked to explain the scene from a distant perspective, as if they were observing an event that occurred to a younger self. Within stage 2 , the goal was to offer some form of intervention rather than just acting as a bystander. Thus, the goal was to create mastery imagery.

Stage 3: The patients were asked to relive the memory again, but this time as if the present adult self was accompanying the younger self. The adult self was encouraged to provide a new perspective on the traumatic memory that had been gained in Phase 1 (cognitive restructuring). The adult self was also encouraged to provide advice to the younger self as they were experiencing the traumatic event. Thus, the goal of stage 3 was to develop compassionate imagery.

When all procedures were completed, patients were asked how they felt. At the end of the imagery rescripting phase, the patients were asked to rate the vividness and distress of the image and the memory, respectively. They were also asked to rate the degree of conviction of their encapsulated belief.

All sessions including ImRs were audiotaped, and participants were encouraged to listen to the recordings as part of their homework.

\section{Quality control}

The CBT was delivered by eight therapists (six clinical psychologists and two psychiatrists) who were experienced in delivering CBT for PD. To confirm all therapists' adherence to 
the protocol and assist with the planning of future sessions for each treatment, all therapists attended weekly group supervision sessions with other therapists and a senior supervisor (E.S.). The senior supervisor also checked the quality of the CBT delivered by the therapists using the Cognitive Therapy Scale-Revised (Blackburn et al., 2001).

\section{Measures}

\section{(1) Outcome measure of the whole CBT}

The outcome measure of our CBT program was the self-reported severity of PD, as measured by the Panic Disorder Severity Scale (PDSS) (Shear et al., 2001). The self-report form of the PDSS (Houck et al., 2002) measures the severity of PD on a 5-point Likert-type scale ranging from 0 (not severe) to 4 (severe); higher scores indicate more severe PD. This scale was adapted from the original, clinician-administered scale (Shear et al., 2001); it is the most frequently used scale for the assessment of PD. The interpretation of the PDSS total score (Furukawa et al., 2009) differed according to the presence or absence of agoraphobia. When the patients were not agoraphobic, score ranges $0-1$ corresponded to 'normal', 2-5 with 'borderline', 6-9 with 'slightly ill', 10-13 with 'moderately ill', and 14 and above with 'markedly ill'. When the patients were agoraphobic, score ranges 3-7 meant 'borderline', 8-10 'slightly ill', 11-15 'moderately ill', and 16 and above 'markedly ill'. The Japanese version of the PDSS was developed by Katagami (2007). Other measures used are shown in Seki et al. (2016). The PDSS (and all measurements in the study of Seki et al., 2016) were conducted before the first session (at week 0; pre-CBT), after the eighth session (week 8; mid-CBT), and after the final session (week 16; post-CBT).

\section{(2) ImRs ratings}

Imagery and memory ratings (vividness and distress). As described in the ImRs procedure (Wild et al., 2008), patients were asked how vivid an image recurrent in panic situations was on a scale ranging from 0 (not at all) to 100 (extremely). They were also asked how distressing the image was on the same scale. The vividness and distress of the early traumatic memory linked to a recurrent image were also rated in the same way.

Encapsulated belief rating. Patients were asked to summarize the meanings of an image that was recurrent in panic situations and related early traumatic memory in one or two sentences as an encapsulated belief. They were then asked to rate how much they believed this statement to be true, on a scale ranging from 0 (not at all) to 100 (extremely). All ImRs ratings were conducted prior to and after the ImRs session.

\section{Statistical analysis}

All statistical tests were two-tailed, and an alpha level of .05 was employed. All data were analysed using SPSS for Windows version 23 (SPSS Inc., Chicago, IL, USA). The outcomes of the CBT for PD were quantified as follows. First, regarding the outcome of our entire CBT program (PDSS scores), we analysed changes between pre-CBT and the other two time points (mid-CBT and post-CBT) using repeated measures, within-subjects analyses of variance (ANOVAs). We performed a non-parametric Wilcoxon signed rank test to compare pre- and post-ImRs ratings, because they were not normally distributed. The effect size $(\gamma=Z / \sqrt{ } 2 n)$ 
was also calculated for changes in each ImRs rating (Field, 2009). According to Cohen (Cohen, 1992), the effect size of the correlation coefficient is categorized as follows: small (0.10-0.29), medium (0.30-0.49) and large (0.50 and above). Finally, we performed a paired $t$-test to determine the correlation between the value obtained by subtracting the post-PDSS score from the pre-PDSS score and the amount of change in each ImRs rating, as these data were normally distributed.

\section{Results}

The characteristics of the participants are given in Table 1.

For images repeatedly appearing in panic situations, $12(80 \%)$ patients had images of symptoms of panic attacks, four (27\%) patients had images of anticipatory anxiety, six (40\%) patients had spatial images (being in a closed space, in a train, at a station, in a dark place, in a large space), and four (27\%) patients had images of loneliness (being understood by no one, being alone, being in a place without acquaintances). Of note, one patient may have had multiple images.

Regarding the initial traumatic memory associated with the recurrent images, nine $(60 \%)$ patients had a memory of the first panic attack, two (13\%) patients had a memory of other panic attacks (one patient had a memory of a second panic attack, another of a feeling experienced as a child that was similar to the current feeling of panic attacks), and four (27\%) patients had memories of events other than panic attacks (absent from school due to vomiting for weeks, seeing my mother suffering from cancer, being misunderstood by a teacher and running away from school, and being criticized by my mother at a party).

Table 2 gives details of individual patients in ImRs.

Table 3 shows themes commonly observed in the worst meaning of images, the worst meaning of memory, and encapsulated beliefs. Self-negative contents not directly related to panic attack were observed in ImRs. Among these, the five representative themes were as follows: 'being worthless', 'being helpless', 'being lonely', 'bothering others', and 'showing embarrassing behaviour in public'.

Table 4 shows pre- and post-scores for ImRs ratings. ImRs significantly reduced distress from images, memories and encapsulated beliefs; however, it did not change the vividness of images and memories. The effect sizes on distress of image, distress of memory, and conviction degree of encapsulated belief were 0.55 (large), 0.43 (medium), and 0.55 (large), respectively. Although the participants in our study were partially different from those in the study of Seki et al. (2016), we obtained a similar result (i.e. a significant reduction in PDSS score). The mean total PDSS score decreased from 13.1 \pm 4.8 at pre-CBT to $8.2 \pm 4.7$ at midCBT and to $6.1 \pm 5.0$ at post-CBT. A repeated measures ANOVA revealed a significant main effect of time point on the PDSS total score: $F(2,28)=28.9, p<.001$; however, there was no significant correlation between the value obtained by subtracting the post-PDSS score from pre-PDSS score and the change amount in each ImRs rating (data not shown). Follow-up data after 1 year were obtained from 10 of 15 patients, and the mean total PDSS score was $5.4 \pm 3.1$.

\section{Discussion}

This study was the first attempt to apply ImRs to PD. We obtained the following results for images, memories, beliefs, and the effect of ImRs on patients with PD. All patients had 
Table 2. Details of individual patients in imagery rescripting

\begin{tabular}{|c|c|c|c|c|c|}
\hline $\mathrm{P}$ & $\begin{array}{l}\text { Recurrent image in panic } \\
\text { situations }\end{array}$ & Worst meanings of image & Memory linked to image & $\begin{array}{l}\text { Worst meanings of } \\
\text { memory }\end{array}$ & Encapsulated belief \\
\hline a & $\begin{array}{l}\text { A fear image in which a } \\
\text { panic attack occurs } \\
\text { under confined } \\
\text { situation. There is no } \\
\text { one who understands } \\
\text { my situation }\end{array}$ & $\begin{array}{l}\text { I expose the disgraceful } \\
\text { behaviour in public. I } \\
\text { feel miserable and } \\
\text { others feel disgusted } \\
\text { with me }\end{array}$ & $\begin{array}{l}\text { I felt intense nausea in a } \\
\text { limited express train. } \\
\text { With a feeling of } \\
\text { irresistible fear, I had } \\
\text { the illusion that the } \\
\text { attention of others was } \\
\text { directed at me }\end{array}$ & $\begin{array}{l}\text { Hopelessness, } \\
\text { helplessness with } \\
\text { no-one to rely on. As } \\
\text { long as I endure } \\
\text { suffering, I will not } \\
\text { annoy anyone }\end{array}$ & $\begin{array}{l}\text { Do not let other people } \\
\text { feel bad, do not bother } \\
\text { others. I should not act } \\
\text { in disgrace. I can only } \\
\text { depend on myself. I } \\
\text { must have a strong } \\
\text { sense of responsibility }\end{array}$ \\
\hline $\mathrm{b}$ & $\begin{array}{l}\text { A person lying on his } \\
\text { back in a dark place } \\
\text { within a large place }\end{array}$ & $\begin{array}{l}\text { I will soon die. I seek } \\
\text { help, but neither I nor } \\
\text { anyone around me can } \\
\text { do anything }\end{array}$ & $\begin{array}{l}\text { Two years ago, at the } \\
\text { Stadium fireworks } \\
\text { festival, I had heart } \\
\text { palpitations and sat } \\
\text { down }\end{array}$ & $\begin{array}{l}\text { I wonder if I am going to } \\
\text { die now }\end{array}$ & $\begin{array}{l}\text { I am alone. I cannot deal } \\
\text { with myself }\end{array}$ \\
\hline $\mathrm{c}$ & $\begin{array}{l}\text { My heart is pounding. I } \\
\text { wonder if I do not have } \\
\text { to go to the toilet }\end{array}$ & $\begin{array}{l}\text { If I were incontinent in } \\
\text { public, it is very scary }\end{array}$ & $\begin{array}{l}\text { It was } 19 \text { years ago, in a } \\
\text { plane going on a Korean } \\
\text { trip with a family, } \\
\text { coming in to land }\end{array}$ & $\begin{array}{l}\text { I cannot behave freely } \\
\text { after having fun. I am } \\
\text { annoying my husband }\end{array}$ & $\begin{array}{l}\text { I do not know why the bad } \\
\text { feeling happened. I do } \\
\text { not know what the cause } \\
\text { is and I cannot help it }\end{array}$ \\
\hline $\mathrm{d}$ & $\begin{array}{l}\text { For a moment, the front of } \\
\text { me is getting dark. After } \\
\text { that I am standing alone } \\
\text { in the dark }\end{array}$ & $\begin{array}{l}\text { I have trouble in the } \\
\text { workplace and in my } \\
\text { surroundings. Alone } \\
\text { and despair. I cannot do } \\
\text { anything by myself }\end{array}$ & $\begin{array}{l}\text { Seven years ago, I got a } \\
\text { job for the first time but } \\
\text { my physical condition } \\
\text { got worse. I quit my job } \\
\text { at last but could hardly } \\
\text { find my next job. I made } \\
\text { my family worry }\end{array}$ & $\begin{array}{l}\text { I cannot live by myself } \\
\text { when my parents are } \\
\text { dead }\end{array}$ & $\begin{array}{l}\text { I cannot live by myself. I } \\
\text { cannot work because I } \\
\text { am socially isolated and } \\
\text { have become useless. I } \\
\text { am an annoying person } \\
\text { who cannot do anything } \\
\text { alone }\end{array}$ \\
\hline
\end{tabular}


Table 2. Continued

\begin{tabular}{|c|c|c|c|c|c|}
\hline $\mathrm{P}$ & $\begin{array}{l}\text { Recurrent image in panic } \\
\text { situations }\end{array}$ & Worst meanings of image & Memory linked to image & $\begin{array}{l}\text { Worst meanings of } \\
\text { memory }\end{array}$ & Encapsulated belief \\
\hline $\mathrm{e}$ & $\begin{array}{l}\text { Feeling that my back is } \\
\text { sinking (like going } \\
\text { down on a roller } \\
\text { coaster). }\end{array}$ & $\begin{array}{l}\text { I cannot go home. What } \\
\text { should I do? }\end{array}$ & $\begin{array}{l}\text { When I was a } \\
\text { kindergarten student, I } \\
\text { was sitting on a child's } \\
\text { chair at the table. I had } \\
\text { a feeling of sinking } \\
\text { (like going down on a } \\
\text { roller coaster) almost } \\
\text { every day }\end{array}$ & $\begin{array}{l}\text { I cannot take the balance } \\
\text { of the body. I do not } \\
\text { know whether my body } \\
\text { is shaking. I cannot } \\
\text { keep my mind normal. I } \\
\text { go crazy }\end{array}$ & $\begin{array}{l}\text { I go insane with fear and } \\
\text { dizziness }\end{array}$ \\
\hline $\mathrm{f}$ & $\begin{array}{l}\text { It is hot and stuffy and I } \\
\text { want some water but I } \\
\text { cannot drink it }\end{array}$ & $\begin{array}{l}\text { I will fall down because I } \\
\text { am dehydrated, and my } \\
\text { falling down will bother } \\
\text { people }\end{array}$ & $\begin{array}{l}\text { When I was in the airport } \\
\text { in Macau, the seats were } \\
\text { narrow and cramped. I } \\
\text { want to go outside and } \\
\text { get some fresh air. I did } \\
\text { not have any drinks }\end{array}$ & $\begin{array}{l}\text { I cannot breathe. I fall } \\
\text { down in } \\
\text { hyperventilation and } \\
\text { feel embarrassed }\end{array}$ & $\begin{array}{l}\text { If I feel stuffy, I will be } \\
\text { overwhelmed with } \\
\text { hyperventilation and go } \\
\text { insane }\end{array}$ \\
\hline $\mathrm{g}$ & $\begin{array}{l}\text { On the train, I am alone in } \\
\text { a space where I cannot } \\
\text { exit. I have numbness in } \\
\text { my limbs. I am afraid } \\
\text { and uncomfortable. I } \\
\text { feel that my } \\
\text { surroundings do not } \\
\text { care about me }\end{array}$ & $\begin{array}{l}\text { I am weak in spirit and } \\
\text { physical strength. I } \\
\text { cannot arrive at my } \\
\text { destination. I cannot } \\
\text { live by myself. I will be } \\
\text { alone if my parents are } \\
\text { dead }\end{array}$ & $\begin{array}{l}\text { When I was in elementary } \\
\text { school, I was absent } \\
\text { from school for two } \\
\text { weeks with nausea, with } \\
\text { a full feeling in my } \\
\text { throat, fear of vomiting }\end{array}$ & $\begin{array}{l}\text { I want to escape from } \\
\text { suffering, but I cannot } \\
\text { run away. I do not know } \\
\text { how to live. I want } \\
\text { someone to help me but } \\
\text { I am suffering only by } \\
\text { myself }\end{array}$ & $\begin{array}{l}\text { I cannot escape from } \\
\text { suffering. I cannot live. } \\
\text { Others cannot } \\
\text { understand me. I am } \\
\text { alone }\end{array}$ \\
\hline h & $\begin{array}{l}\text { My heartbeats will turn } \\
\text { into myocardial } \\
\text { infarction }\end{array}$ & $\begin{array}{l}\text { I will have a myocardial } \\
\text { infarction }\end{array}$ & $\begin{array}{l}\text { One night a little bit after } \\
\text { my parents died, I } \\
\text { stayed in bed and it } \\
\text { became stuffy }\end{array}$ & $\begin{array}{l}\text { I will collapse due to heart } \\
\text { disease }\end{array}$ & $\begin{array}{l}\text { When the palpitations } \\
\text { start, they get stronger } \\
\text { and stronger, and I fall } \\
\text { down due to my heart }\end{array}$ \\
\hline
\end{tabular}


Table 2. Continued

\begin{tabular}{|c|c|c|c|c|c|}
\hline $\mathrm{P}$ & $\begin{array}{l}\text { Recurrent image in panic } \\
\text { situations }\end{array}$ & Worst meanings of image & Memory linked to image & $\begin{array}{l}\text { Worst meanings of } \\
\text { memory }\end{array}$ & Encapsulated belief \\
\hline $\mathrm{i}$ & $\begin{array}{l}\text { I am suffering from an } \\
\text { overwhelming stroke. I } \\
\text { am in pain. I cannot } \\
\text { breathe. I am sweating }\end{array}$ & $\begin{array}{l}\text { I press the emergency } \\
\text { button to escape, open } \\
\text { the door and get out. I } \\
\text { make a fuss }\end{array}$ & $\begin{array}{l}\text { Over } 20 \text { years ago, in a } \\
\text { very crowded train. It } \\
\text { was rainy and humid. I } \\
\text { was suddenly } \\
\text { suffocating. I became } \\
\text { scared, pushed through } \\
\text { the crowd and hit the } \\
\text { doors of the conductor's } \\
\text { booth, saying, 'Please } \\
\text { help me!' }\end{array}$ & I am very ashamed & $\begin{array}{l}\text { Panic disorder picks } \\
\text { people. The chosen } \\
\text { person has serious flaws }\end{array}$ \\
\hline $\mathrm{j}$ & The collapse of my heart & My heart stops & $\begin{array}{l}\text { Thirteen years ago, my } \\
\text { mother was in the end } \\
\text { stages of cancer and I } \\
\text { saw her suffering in the } \\
\text { hospital }\end{array}$ & $\begin{array}{l}\text { I should have been able to } \\
\text { do something more }\end{array}$ & $\begin{array}{l}\text { I needed to do something } \\
\text { more, but I did not do it }\end{array}$ \\
\hline $\mathrm{k}$ & $\begin{array}{l}\text { I am conscious only of } \\
\text { myself, blocked from } \\
\text { the outside }\end{array}$ & $\begin{array}{l}\text { Air is not enough. I'm } \\
\text { almost screaming with } \\
\text { scare. I will not be able } \\
\text { to take my breath }\end{array}$ & $\begin{array}{l}\text { When I was conscious of } \\
\text { breathing in the } \\
\text { washroom, I became } \\
\text { more and more } \\
\text { concerned about it }\end{array}$ & $\begin{array}{l}\text { I cannot breathe. I will die } \\
\text { by suffocation }\end{array}$ & $\begin{array}{l}\text { I cannot breathe. I will } \\
\text { collapse and die }\end{array}$ \\
\hline 1 & $\begin{array}{l}\text { I am suffering from } \\
\text { unnatural breathing. } \\
\text { The people around me } \\
\text { are strangers. They see } \\
\text { me as a strange person } \\
\text { with unnatural } \\
\text { breathing }\end{array}$ & $\begin{array}{l}\text { I suffer from my } \\
\text { breathing. I collapse } \\
\text { and nobody helps me. I } \\
\text { will lose consciousness } \\
\text { and die in this way }\end{array}$ & $\begin{array}{l}\text { When I was a high school } \\
\text { student, my heart } \\
\text { palpitated; I could not } \\
\text { stay calm. The health } \\
\text { teacher asked me what } \\
\text { was wrong, but I myself } \\
\text { did not know what } \\
\text { happened and I could } \\
\text { not explain it well }\end{array}$ & $\begin{array}{l}\text { Others understand } \\
\text { hyperventilation when } \\
\text { seen from the outside. } \\
\text { But they do not know } \\
\text { the panic feeling, so I } \\
\text { cannot get help. My } \\
\text { hyperventilation is } \\
\text { different from that of } \\
\text { others, so it will not } \\
\text { heal }\end{array}$ & $\begin{array}{l}\text { Even though I did CBT, I } \\
\text { had a relapse. It may } \\
\text { also recur. I will never } \\
\text { be cured for life. I } \\
\text { cannot fulfil my } \\
\text { responsibility as the } \\
\text { family's breadwinner }\end{array}$ \\
\hline
\end{tabular}


Table 2. Continued

\begin{tabular}{|c|c|c|c|c|c|}
\hline$P$ & $\begin{array}{l}\text { Recurrent image in panic } \\
\text { situations }\end{array}$ & Worst meanings of image & Memory linked to image & $\begin{array}{l}\text { Worst meanings of } \\
\text { memory }\end{array}$ & Encapsulated belief \\
\hline $\mathrm{m}$ & $\begin{array}{l}\text { Image that is to anxiety on } \\
\text { the train. My hands are } \\
\text { rigid and I felt my body } \\
\text { was dying }\end{array}$ & $\begin{array}{l}\text { Because of suffering to } \\
\text { the extent of death, I act } \\
\text { abnormally enough to } \\
\text { make myself funny to } \\
\text { others. I harm people. I } \\
\text { get crazy }\end{array}$ & $\begin{array}{l}\text { Two years ago, when I } \\
\text { was on a train, a panic } \\
\text { attack occurred. My } \\
\text { blood rose at the } \\
\text { moment and my } \\
\text { consciousness was on } \\
\text { the brink of being lost }\end{array}$ & $\begin{array}{l}\text { I am afraid to get on the } \\
\text { train and it is } \\
\text { impossible. I cannot do } \\
\text { my best any longer. } \\
\text { Exposure to the train is } \\
\text { impossible now }\end{array}$ & $\begin{array}{l}\text { The train is scary. It is } \\
\text { impossible to get on }\end{array}$ \\
\hline $\mathrm{n}$ & $\begin{array}{l}\text { A sense of fear and } \\
\text { anxiety comes up all at } \\
\text { once. Suddenly fear } \\
\text { comes out. There is no } \\
\text { place to escape, only to } \\
\text { endure }\end{array}$ & $\begin{array}{l}\text { I am afraid of panic } \\
\text { attacks. I am afraid to } \\
\text { bound by the sense of } \\
\text { fear. I want to meet my } \\
\text { parents' expectations } \\
\text { but panic prevents it. I } \\
\text { want to be cured, but it } \\
\text { is not going well }\end{array}$ & $\begin{array}{l}\text { About ten years ago, } \\
\text { during a party, my } \\
\text { mother kept blaming me } \\
\text { loudly. She also told me } \\
\text { 'There is no such cruel } \\
\text { child like you' }\end{array}$ & $\begin{array}{l}\text { My mother breaks } \\
\text { everything. My mother } \\
\text { breaks the people and } \\
\text { things that I care about }\end{array}$ & $\begin{array}{l}\text { My mother breaks people } \\
\text { and things precious to } \\
\text { me at her convenience }\end{array}$ \\
\hline $\mathrm{o}$ & $\begin{array}{l}\text { A stretcher, a wheelchair. } \\
\text { There are four to five } \\
\text { station staff. I guess } \\
\text { others will be late }\end{array}$ & $\begin{array}{l}\text { I am sorry to disturb } \\
\text { others. I am taking extra } \\
\text { care. It is bad though it } \\
\text { is a simple panic attack. } \\
\text { Although it is not a big } \\
\text { deal, I am annoying } \\
\text { others }\end{array}$ & $\begin{array}{l}\text { When I was in the fourth } \\
\text { grade of elementary } \\
\text { school, my teacher } \\
\text { misunderstood me as } \\
\text { being rebellious and } \\
\text { ordered me to go home. } \\
\text { I left school and hid in } \\
\text { the house of my } \\
\text { grandmother. My } \\
\text { mother was very } \\
\text { worried and protested to } \\
\text { my teacher in tears }\end{array}$ & $\begin{array}{l}\text { I did not solve my } \\
\text { problem when I had it, } \\
\text { causing inconvenience } \\
\text { to people }\end{array}$ & $\begin{array}{l}\text { In a trivial matter such as } \\
\text { panic, I am annoying } \\
\text { people. I did not do } \\
\text { what I had to do. I did } \\
\text { something I should not } \\
\text { do. I worried my mother }\end{array}$ \\
\hline
\end{tabular}


Table 3. Themes in the meaning of images and memories, encapsulated beliefs $(N=15)$

\begin{tabular}{llll}
\hline & \multicolumn{2}{c}{ Worst meanings of } & \\
\cline { 2 - 3 } Theme & $\begin{array}{l}\text { Recurrent } \\
\text { images }(n)\end{array}$ & $\begin{array}{l}\text { Traumatic } \\
\text { events }(n)\end{array}$ & $\begin{array}{l}\text { Encapsulated } \\
\text { beliefs }(n)\end{array}$ \\
\hline Anticipatory anxiety & 9 & 6 & 5 \\
Being useless or worthless & 2 & 1 & 4 \\
Being powerless, unable to live alone & 4 & 4 & 4 \\
Being lonely, not understood or without help & 3 & 3 & 4 \\
Bothering others & 4 & 2 & 4 \\
Showing embarrassing behaviour in public & 4 & 0 & 1 \\
Being ashamed & 0 & 2 & 0 \\
PD is never cured/the cause of PD is unknown & 0 & 1 & 2 \\
My life is not going well/life is hopeless & 2 & 1 & 1 \\
Being damaged by my parent(s) & 0 & 2 & 1 \\
I must have a strong sense of responsibility & 0 & 0 & 1 \\
\hline
\end{tabular}

Note: One patient may have multiple meanings and beliefs. PD, panic disorder.

Table 4. Pre- and post-ImRs ratings $(N=15)$

\begin{tabular}{llllll}
\hline \multirow{2}{*}{ ImRs ratings } & Pre-ImRs & Post-ImRs & \multicolumn{3}{c}{ Analysis } \\
\cline { 2 - 6 } & Median (IQR) & Median (IQR) & $Z$ & $p$ & $r$ \\
\hline Image vividness & $77.5(27.5-97.5)$ & $70.0(50.0-100)$ & -0.071 & .94 & 0.014 \\
Image distress & $87.5(67.5-100)$ & $55.0(30.0-70.0)$ & -2.92 & $.004^{* *}$ & 0.55 \\
Memory vividness & $80.0(60.0-100)$ & $70.0(50.0-100)$ & -0.94 & .35 & 0.18 \\
Memory distress & $80.0(40.0-100)$ & $40.0(30.0-85.0)$ & -2.36 & $.018^{*}$ & 0.43 \\
Encapsulated belief & $90.0(50.0-100)$ & $60.0(23.8-80.0)$ & -2.91 & $.004^{* *}$ & 0.55 \\
\hline
\end{tabular}

ImRs, imagery rescripting; IQR, interquartile range; $r$, effect size; ${ }^{*} p<.05,{ }^{* *} p<.01$.

recurrent images in panic situations. Among the images that the patients had were an image of symptoms of panic attacks, anticipatory anxiety, an image of being confined in a closed space, and an image of loneliness. The spatial image seemed related to agoraphobia; however, the loneliness images are not necessarily related to panic attacks.

The meanings of image, memory and encapsulated beliefs were idiosyncratic and patient specific, relating to individual trauma experiences. However, self-negative contents not directly related to symptoms of panic attack were observed as common themes beyond the differences of individual patients. These themes may be related to the persistence of panic symptoms by controlling patients' thoughts and indirectly affecting emotion, behaviour and body sensation. Depression and SAD are known to often be co-morbid with PD; among the themes observed in ImRs, the self-negative contents of being worthless, being helpless and being lonely may be involved in depression. Those of bothering others and showing embarrassing behaviour in public may be seen within SAD. The process of treating such themes is not included in conventional CBT for PD. Therefore, it is considered clinically meaningful to add ImRs sessions to conventional CBT. 
ImRs significantly reduced the distress of images and memories. Even though these did not lead to the creation of new functional beliefs, the confidence of maladaptive beliefs was decreased. However, it did not change the vividness of images and memories. This result suggests that the series of processes of ImRs alleviated the pain of traumatic memory and corrected the non-functional and biased beliefs derived from the memory. As these images and memories were evoked during ImRs, it is natural that the vividness of the image and the memory did not decrease after ImRs.

We assumed that the correlation between changes in PDSS scores and changes in encapsulated beliefs would reflect mechanisms of change. Contrary to our expectation, there was no significant correlation between the reduction in the severity of the PD (as measured by PDSS) over the course of the whole CBT program and the change in each ImRs rating. The CBT conducted in this study included other sessions than ImRs. While ImRs session were placed in the second half of the CBT, the change in the PDSS score was larger in the amount of change from pre- to mid-treatment than from mid- to post-treatment. Improvement at the symptomatic level of PD seems to be mostly obtained in the first half of CBT. The first half of the CBT included conventional CBT components such as behavioural experiments on the presence or absence of safety behaviours and catastrophic self-image reconstruction, resulting from the misinterpretations of bodily sensations. These sessions are considered to sufficiently alleviate the symptoms of PD.

To date, several authors have specifically written about proposed mechanisms of change in ImRs. For example, Arntz suggested that ImRs is a psychological means to change the original memory and the content of the memory-related working selves (e.g. Arntz and Weertman, 1999; Arntz, 2011). Others have suggested that individuals have different self-representations that are activated in response to memory recall, and whose accessibility may be modified as a result of ImRs (e.g. Brewin, 2006; Brewin et al., 2009; Çili et al., 2017). However, based on the results of this study, it is not possible to suggest how probable mechanisms of ImRs are. Mechanisms aside, the question of the role of ImRs in the treatment of PD remains. Two studies suggest an answer to the question. Long et al. (2011b) analysed data from ImRs performed in the treatment of post-traumatic nightmares (PTNMs), suggesting that modification of post-traumatic cognitions is a mechanism of change when using a manualized PTNM ImRs intervention, and ImRs may bring about a long-term improvement in trauma-related cognitions. Veale et al. (2015) performed a single ImRs on patients with OCD. They found that the score of the Yale-Brown Obsessive Compulsive Scale was even lower after 3 months than immediately after ImRs. These studies suggest that ImRs plays an important role in maintaining the long-term stability of a panic-free state, recovery from posttraumatic symptoms, and the prevention of recurrence. In our study, remission of PD has been maintained in 10 out of 15 patients based on follow-up data. However, as to whether ImRs contributes to maintenance of remission, evaluation (such as re-measurement of ImRs ratings) is necessary.

\section{Limitations}

The limitations of this study include the following: no control group was set, the sample size was small, there was a large sex bias among participants, and there was a lack of follow-up data on ImRs ratings. Further investigation is required for the effectiveness of ImRs for PD. It is ultimately necessary to deal with the subject of this research in a randomized controlled 
trial that gathers larger, more diverse samples, devises a follow-up period, and is performed at multiple institutions. Further refinement will be necessary for the cognitive model of PD, which is the basis of the effectiveness of ImRs. Furthermore, ImRs is not mandatory for all patients with PD. Even using conventional CBT without ImRs, many patients recover. Therefore, it is necessary to develop a method to predict what PD patients need ImRs.

\section{Main points}

(1) This study explored the therapeutic effects of ImRs on patients with PD to change the meaning of images and associated memories and reduce emotional distress.

(2) ImRs significantly reduced distress from images, memories and encapsulated beliefs; however, it did not change the vividness of images and memories.

(3) There was no significant correlation between the reduction in PD severity over the CBT program and the change in each rating (vividness and distress of the images and memories and conviction degree of encapsulated beliefs) in ImRs.

\section{Acknowledgements}

The authors wish to thank the anonymous reviewers for comments on an earlier version of this paper.

\section{Conflicts of interest}

Takayuki Shibuya, Yoichi Seki, Shinobu Nagata, Tomokazu Murata, Yoichi Hiramatsu, Fuminori Yamada, Mizue Yokoo, Hanae Ibuki, Noriko Minamitani, Mari Tanaka and Eiji Shimizu have no conflicts of interest with respect to this publication.

\section{Ethical statements}

The present paper followed the Ethical Principles of Psychologists and Code of Conduct as set out by the American Psychiatric Association. The Ethics Committee of the Chiba University Graduate School of Medicine approved the study protocol (reference number 1710).

\section{Financial support}

This study was supported by the Japanese Ministry of Health, Labour and Welfare under a Grant-in-Aid for Scientific Research (grant no. 22SE1P0051) (to E.S.); the Japanese Ministry of Education, Culture, Sports, Science and Technology under a part of the Special Budget for Projects (to E.S.); and Pfizer Academic Contributions (to E.S.). E.S. has received speaking honoraria at medical education events supported by Eisai, Eli Lilly, GSK, Janssen, Meiji Seika, Mochida, MSD, Otsuka, Pfizer and Yoshitomi. The funding sources had no role in the design and conduct of the study; in the collection, management, analysis and interpretation of the data; in the preparation, review or approval of the manuscript; or in the decision to submit the manuscript for publication. 


\section{Recommended follow-up reading}

Arntz A (2012). Imagery rescripting as a therapeutic technique: review of clinical trials, basic studies, and research agenda. Journal of Experimental Psychopathology 3, 189-208.

Reimer SG, Moscovitch DA (2015). The impact of imagery rescripting on memory appraisals and core beliefs in social anxiety disorder. Behaviour Research and Therapy, 75, 48-59.

\section{References}

Afkham AZ, Toghchi MS (2012). The effectiveness of imagery rescripting and reprocessing therapy on reduction of subjective units of distress and recurrent images on war disabled with PTSD. European Psychiatry 27, 1-12. doi: 10.1016/s0924-9338(12)75342-7

American Psychiatric Association (2013). DSM-5. Diagnostic and Statistical Manual of Mental Disorders.

American Psychiatric Association (2009). Practice guideline for the treatment of patients with panic disorder: second edition. American Journal of Psychiatry 166, 1-68.

Arntz A, Weertman A (1999). Treatment of childhood memories: theory and practice. Behaviour Research and Therapy 37, 715-740.

Arntz A (2011). Imagery rescripting for personality disorders. Cognitive and Behavioral Practice 18, 466-481.

Arntz A (2012). Imagery rescripting as a therapeutic technique: review of clinical trials, basic studies, and research agenda. Journal of Experimental Psychopathology 3, 189-208.

Arntz A, Sofi D, van Breukelen G (2013). Imagery rescripting as treatment for complicated PTSD in refugees: a multiple baseline case series study. Behaviour Research and Therapy 51, 274-283.

Arntz A, Tiesema M, Kindt M (2007). Treatment of PTSD: a comparison of imaginal exposure with and without imagery rescripting. Journal of Behavior Therapy and Experimental Psychiatry 38, 345370.

Batelaan NM, Van Balkom AJLM, Stein DJ (2011). Evidence-based pharmacotherapy of panic disorder: an update. International Journal of Neuropsychopharmacology/Official Scientific Journal of the Collegium Internationale Neuropsychopharmacologicum (CINP) 8, 1-13.

Blackburn IM, James IA, Milne DL, Baker C, Standart S, Garland A, Reichelt FK (2001). The Revised Cognitive Therapy Scale (CTS-R): psychometric properties. Behavioural and Cognitive Psychotherapy 29, 431-446.

Brewin CR (2006). Understanding cognitive behaviour therapy: a retrieval competition account. Behaviour Research and Therapy 44, 765-784.

Brewin CR, Wheatley J, Patel T, Fearon P, Hackmann A, Wells A, Fisher P, Myers S (2009). Imagery rescripting as a brief stand-alone treatment for depressed patients with intrusive memories. Behaviour Research and Therapy 47, 569-576.

Çili S, Pettit S, Stopa L (2017). Impact of imagery rescripting on adverse self-defining memories and post-recall working selves in a non-clinical sample: a pilot study. Cognitive Behaviour Therapy 46, 75-89.

Clark DM (1986). A cognitive approach to panic. Behaviour Research and Therapy 24, 461-470.

Clark DM, Ehlers A, McManus F, Hackmann A, Fennell M, Campbell H, Flower T, Davenport C, Louis B (2003). Cognitive therapy versus fluoxetine in generalized social phobia: a randomized placebo-controlled trial. Journal of Consulting and Clinical Psychology 71, 1058-1067

Clark DM, Ehlers A, Hackmann A, McManus F, Fennell M, Grey N, Waddington L, Wild J (2006). Cognitive therapy versus exposure and applied relaxation in social phobia: a randomized controlled trial. Journal of Consulting and Clinical Psychology 74, 568-578. 
Clark DM, Salkovskis PM, Hackmann A, Middleton H, Anastasiades P, Gelder M (1994). A comparison of cognitive therapy, applied relaxation and imipramine in the treatment of panic disorder. British Journal of Psychiatry 164, 759-769.

Clark DM, Salkovskis PM, Ost LG, Breitholtz E, Koehler KA, Westling BE, Jeavons A, Gelder M (1997). Misinterpretation of body sensations in panic disorder. Journal of Consulting and Clinical Psychology 65, 203-213.

Clark DM, Wells A (1995). A cognitive model of social phobia. Social Phobia: Diagnosis, Assessment, and Treatment 41, 22-23.

Cohen J (1992). A power primer. Psychological Bulletin 112, 155-159.

Day SJ, Holmes EA, Hackmann A (2004). Occurrence of imagery and its link with early memories in agoraphobia. Memory 12, 416-427.

Edwards DJA (2007). Restructuring implicational meaning through memory-based imagery: Some historical notes. Journal of Behavior Therapy and Experimental Psychiatry 38, 306316.

Ehlers A, Clark DM (2000). A cognitive model of posttraumatic stress disorder. Behaviour Research and Therapy 28, 319-345.

Field A (2009). Discovering Statistics Using SPSS. Sage Publications.

Frets PG, Kevenaar C, Van Der Heiden C (2014). Imagery rescripting as a stand-alone treatment for patients with social phobia: a case series. Journal of Behavior Therapy and Experimental Psychiatry 45, 160-169.

Furukawa TA, Shear MK, Barlow DH, Gorman MD, Woods SW, Money R, Etschel E, Engel RR, Leucht S (2009). Evidence-based guidelines for interpretation of the Panic Disorder Severity Scale. Depression and Anxiety 26, 922-929.

Hackmann A (2011). Imagery rescripting in posttraumatic stress disorder. Cognitive and Behavioral Practice 18, 424-432.

Hackmann A, Clark DM, McManus F (2000). Recurrent images and early memories in social phobia. Behaviour Research and Therapy 38, 601-610.

Hagennars MA, Holmes EA (2012). Imagery in psychopathology: another step (editorial for the special issue of Journal of Experimental Psychopathology). Journal of Experimental Psychopathology 3, 121-126.

Hagenaars MA, van Minnen A, Hoogduin CAL, Verbraak M (2009). A transdiagnostic comparison of trauma and panic memories in PTSD, panic disorder, and healthy controls. Journal of Behavior Therapy and Experimental Psychiatry 40, 412-422.

Hoffart A, Øktedalen T, Langkaas TF, Wampold BE (2013). Alliance and outcome in varying imagery procedures for PTSD: a study of within-person processes. Journal of Counseling Psychology 60, 471-482.

Houck PR, Spiegel DA, Shear MK, Rucci P (2002). Reliability of the self-report version of the panic disorder severity scale. Depression and Anxiety 15, 183-185.

Hunt M, Fenton M (2007). Imagery rescripting versus in vivo exposure in the treatment of snake fear. Journal of Behavior Therapy and Experimental Psychiatry 38, 329-344.

Ison R, Medoro L, Keen N, Kuipers E (2014). The use of rescripting imagery for people with psychosis who hear voices. Behavioural and Cognitive Psychotherapy 42, 129-142.

Katagami M (2007). The self-report version of the Panic Disorder Severity Scale: reliability and validity of the Japanese version. Japan Journal of Psychosomatic Medicine 47, 331-338.

Kessler RC, Chiu WT, Jin R, Ruscio AM, Shear K, Walters EE (2006). The epidemiology of panic attacks, panic disorder, and agoraphobia in the National Comorbidity Survey Replication. Archives of General Psychiatry 63, 415-424.

Laposa JM, Collimore KC, Rector NA (2014). Is post-event processing a social anxiety specific or transdiagnostic cognitive process in the anxiety spectrum? Behavioural and Cognitive Psychotherapy 42, 706-717. 
Layden MA, Newman CF, Freeman A, Morse SB (1993). Cognitive Therapy of Borderline Personality Disorder. Boston: Allyn and Bacon.

Lee SW, Kwon JH (2013). The efficacy of imagery rescripting (IR) for social phobia: a randomized controlled trial. Journal of Behavior Therapy and Experimental Psychiatry 44, 351-360.

Long ME, Davis JL, Springer JR, Elhai JD, Rhudy JL, Teng EJ, Frueh BC (2011a). The role of cognitions in imagery rescripting for posttraumatic nightmares. Journal of Clinical Psychology 67, 1008-1016.

Long ME, Hammons ME, Davis JL, Frueh BC, Khan MM, Elhai JD, Teng EJ (2011b). Imagery rescripting and exposure group treatment of posttraumatic nightmares in veterans with PTSD. Journal of Anxiety Disorders 25, 531-535.

Long ME, Quevillon R (2009). Imagery rescripting in the treatment of posttraumatic stress disorder. Journal of Cognitive Psychotherapy 23, 67-76.

Moritz S, Hörmann CC, Schröder J, Berger T, Jacob GA, Meyer B, Holmes EA (2014). Beyond words: sensory properties of depressive thoughts. Cognition and Emotion 28, 1047-1056.

Mortberg E, Clark DM, Sundin O, Wistedt (2007). Intensive group cognitive therapy and individual cognitive therapy versus treatment as usual in social phobia: a randomized controlled trial. Acta Psyichiatrica Scandinavica 115, 142-154.

Nilsson JE, Lundh LG, Viborg G (2012). Imagery rescripting of early memories in social anxiety disorder: an experimental study. Behaviour Research and Therapy 50, 387-392.

Norton AR, Abbott MJ (2016). The efficacy of imagery rescripting compared to cognitive restructuring for social anxiety disorder. Journal of Anxiety Disorders 40, 18-28.

Ohanian V (2001). Imagery rescripting within cognitive behavior therapy for bulimia nervosa: an illustrative case report. International Journal of Eating Disorders 31, 352-357.

Otsubo T, Tanaka K, Koda R, Shinoda J, Sano N, Tanaka S, Hiroshi A, Masaru M, Kamijima K (2005). Reliability and validity of Japanese version of the Mini-International Neuropsychiatric Interview. Psychiatry and Clinical Neurosciences 59, 517-526.

Pajak R, Kamboj SK (2014). Experimental single-session imagery rescripting of distressing memories in bowel/bladder-control anxiety: a case series. Frontiers in Psychiatry 5, 182.

Patel T, Brewin CR, Wheatley J, Wells A, Fisher P, Myers S (2007). Intrusive images and memories in major depression. Behaviour Research and Therapy 45, 2573-2580.

Philips C, Samson D (2012). The rescripting of pain images. Behavioural and Cognitive Psychotherapy 40, 558-576.

Prasko J, Grambal A, Ociskova M, Kamaradova D, Latalova K (2015). Imagery rescripting of traumatic or distressing stories from childhood. European Psychiatry 30, 1637.

Raabe S, Ehring T, Marquenie L, Olff M, Kindt M (2015). Imagery rescripting as stand-alone treatment for posttraumatic stress disorder related to childhood abuse. Journal of Behavior Therapy and Experimental Psychiatry 48, 170-176.

Reimer SG, Moscovitch DA (2015). The impact of imagery rescripting on memory appraisals and core beliefs in social anxiety disorder. Behaviour Research and Therapy 75, 48-59.

Ritter V, Stangier U (2016). Seeing in the mind's eye: imagery rescripting for patients with body dysmorphic disorder. A single case series. Journal of Behavior Therapy and Experimental Psychiatry 50, 187-195.

Roshanaei-Moghaddam B, Pauly MC, Atkins DC, Baldwin SA, Stein MB, Roy-Byrne P (2011). Relative effects of CBT and pharmacotherapy in depression versus anxiety: is medication somewhat better for depression, and CBT somewhat better for anxiety? Depression and Anxiety 28, 560-567.

Salkovskis PM, Clark DM, Hackmann A, Wells A, Gelder MG (1999). An experimental investigation of the role of safety-seeking behaviours in the maintenance of panic disorder with agoraphobia. Behaviour Research and Therapy 37, 559-574.

Seki Y, Nagata S, Shibuya T, Yoshinaga N, Yokoo M, Ibuki H, Minamitani N, Kusunoki M, Inada Y, Kawasoe N, Adachi S (2016). A feasibility study of the clinical effectiveness and 
cost-effectiveness of individual cognitive behavioral therapy for panic disorder in a Japanese clinical setting: an uncontrolled pilot study. BMC Research Notes 9, 458.

Shear MK, Rucci P, Williams J, Frank E, Grochocinski V, Vander Bilt J, Houck P, Wang T (2001). Reliability and validity of the Panic Disorder Severity Scale: replication and extension. Journal of Psychiatric Research 35, 293-296.

Sheehan DV, Lecrubier Y, Sheehan KH, Amorim P, Janavs J, Weiller E, Hergueta T, Baker R, Dunbar GC (1998). The Mini-International Neuropsychiatric Interview (MINI): the development and validation of a structured diagnostic psychiatric interview for DSM-IV and ICD-10. Journal of Clinical Psychiatry 59, 22-33.

Slofstra C, Nauta MH, Holmes EA, Bockting CLH (2016). Imagery rescripting: the impact of conceptual and perceptual changes on aversive autobiographical memories. PLOS One 11, e0160235e0160235.

Smucker MR, Dancu C, Foa EB, Niederee JL (1995). Imagery rescripting: a new treatment for survivors of childhood sexual abuse suffering from posttraumatic stress. Journal of Cognitive Psychotherapy 9, 3-17.

Stangier U, Heidenreich T, Peitz M, Lauterbach W, Clark DM (2003). Cognitive therapy for social phobia: individual versus group treatment. Behaviour Research and Therapy 41, 991-1007.

Stopa L (2011). Imagery rescripting across disorders: a practical guide. Cognitive and Behavioural Practice 18, 421-423.

Veale D, Page N, Woodward E, Salkovskis P (2015). Imagery rescripting for obsessive compulsive disorder: a single case experimental design in 12 cases. Journal of Behavior Therapy and Experimental Psychiatry 49, 230-236.

Wells A (1990). Panic disorder in association with relaxation induced anxiety: an attentional training approach to treatment. Behavior Therapy 21, 273-280.

Wells A, White J, Carter K (1997). Attention training: effects on anxiety and beliefs in panic and social phobia. Clinical Psychology and Psychotherapy 4, 226-232.

Wenzel A, Cochran CK (2006). Autobiographical memories prompted by automatic thoughts in panic disorder and social phobia. Cognitive Behaviour Therapy 35, 129-137.

Wenzel A, Sharp IR, Brown GK, Greenberg RL, Beck AT (2006). Dysfunctional beliefs in panic disorder: the Panic Belief Inventory. Behaviour Research and Therapy 44, 819-833.

Wheatley J, Brewin CR, Patel T, Hackmann A, Wells A, Fisher P, Myers S (2007). 'I'll believe it when I can see it': imagery rescripting of intrusive sensory memories in depression. Journal of Behavior Therapy and Experimental Psychiatry 38, 371-385.

Whitaker KL, Brewin CR, Watson M (2010). Imagery rescripting for psychological disorder following cancer: a case study. British Journal of Health Psychology 15, 41-50.

Wild J, Clark DM (2011). Imagery rescripting of early traumatic memories in social phobia. Cognitive and Behavioral Practice 18, 433-443.

Wild J, Hackmann A, Clark DM (2007). When the present visits the past: updating traumatic memories in social phobia. Journal of Behavior Therapy and Experimental Psychiatry 38, 386-401.

Wild J, Hackmann A, Clark DM (2008). Rescripting early memories linked to negative images in social phobia: a pilot study. Behavior Therapy 39, 47-56.

Willson R, Veale D, Freeston M (2016). Imagery rescripting for body dysmorphic disorder: a multiplebaseline single-case experimental design. Behavior Therapy 47, 248-261.

Young JE, Lindemann MD (1992). An integrative schema-focused model for personality disorders. Journal of Cognitive Psychotherapy 6, 11-24. 


\section{Learning objectives}

(1) To understand the procedure of ImRs in CBT for PD.

(2) To recognize that some patients with PD have self-negative contents not directly related to symptoms of panic attacks as common themes in the worst meaning of the image, the memory, and in the encapsulated belief.

(3) To appreciate that ImRs might be potentially effective in treating some patients with PD. 